\title{
Market access of Chinese patent medicine products to healthcare security system in China: implications for international integration of traditional medicine into health systems
}

\author{
Chenglai Xia ${ }^{1,2}$, Dongning Yao ${ }^{3}$, Yunfeng $\mathrm{Lai}^{4}$, Yan Xue ${ }^{3}$ and $\mathrm{HaO} \mathrm{Hu}^{3,5^{*}}$
}

\begin{abstract}
Background: China has introduced a series of polices and practice to manage the market access of Chinese patent medicine (CPM) products into its healthcare security system, which is less analyzed and reported in current literature. Therefore, this paper aimed to investigate the mechanisms managing market access of CPM products into healthcare security system in China, expecting to provide implications for international integration of traditional medicine products into health systems.

Method: This paper used a documentary analysis approach as a qualitative research method. Data were collected from four sources and analyzed in a thematic way.

Results: Four mechanisms to manage entry, price adjustment, and exit of innovative brand and generic CPM products are identified, including: (1) price negotiation, mechanism of new entry of innovative brand CPM products into the national reimbursement list; (2) price re-negotiation, mechanism of price adjustment of innovative brand CPM products within the national reimbursement list; (3) mass procurement, mechanism of generic CPM products to healthcare security system; and (4) direct removal, mechanism of removal from the national reimbursement list.

Conclusions: China has established market access framework of CPM products by focusing on price negotiation for innovative brand CPM products and mass procurement for generic CPM products. Further studies of CPM products based real-world data are needed to provide clinical and pharmacoeconomic evidence to support market access of CPM products into healthcare security systems.
\end{abstract}

Keywords: Chinese patent medicine, Chinese medicine, Market access, Healthcare security system, Price negotiation, Pharmacoeconomics

\section{Background}

With the application of modern science and technology into development of traditional medicine product, public acceptance of traditional medicine products is continuously increasing $[1,2]$. However, traditional medicine

\footnotetext{
*Correspondence: haohu@um.edu.mo

${ }^{5}$ Department of Public Health and Medicinal Administration, Faculty of Health Sciences, University of Macau, Macao, SAR, China

Full list of author information is available at the end of the article
}

products still face extraordinary challenges of market access into healthcare security systems [3-5]. In particular, compared with the relatively developed market access institutions for conventional medicine products, institutional arrangement of market access of traditional medicine products remains blank in most healthcare security systems [6].

China is one of the countries that have widely used traditional medicine products in their healthcare security original author(s) and the source, provide a link to the Creative Commons licence, and indicate if changes were made. The images or other third party material in this article are included in the article's Creative Commons licence, unless indicated otherwise in a credit line to the material. If material is not included in the article's Creative Commons licence and your intended use is not permitted by statutory regulation or exceeds the permitted use, you will need to obtain permission directly from the copyright holder. To view a copy of this licence, visit http://creativecommons.org/licenses/by/4.0/. The Creative Commons Public Domain Dedication waiver (http://creativeco mmons.org/publicdomain/zero/1.0/) applies to the data made available in this article, unless otherwise stated in a credit line to the data. 
systems [7]. Chinese patent medicine (CPM) products are often applied for treatment and maintenance since the foundation of the People's Republic of China in 1949 $[8,9]$. But there were no standardized regulations for managing market access of CPM products into healthcare security system for a long period. The health departments mostly rely on historical utilization tradition and experts' opinions to decide the inclusion or exclusion of CPM products for healthcare security, which raised much criticisms from the public and industry [10].

To meet the challenges of regulating market access of CPM products, the National Healthcare Security Administration (NHSA) of China and the related ministries such as the National Medicinal Product Administration (NMPA) and the National Health Commission (NHC), etc., had introduced a series of policies and experimented some innovative practices in the past years. With these reforms in market access regulations, market access of CPM products has been mostly operated in an institutionalized routine. On 28th December 2020 the NHSA officially publicized the "National Basic Medical Insurance, Work Injury Insurance and Maternity Insurance Drug List (2020)" (so-called the national reimbursement list (2020)). Among the 2,800 drugs included into the reimbursement list, there are 1,315 CPM products, showing a significant access of CPM products to the healthcare security system. However, these policy and regulation changes for market access of CPM products into healthcare security system have not been systematically analyzed and reported in current literature.

Therefore, in this paper, we aimed to investigate the mechanisms managing market access of CPM products into healthcare security system in China. It is expected that the findings can generate evidence for future optimization of market access policies for CPM products in China. Also, it is expected that the findings can provide references for international innovation of traditional medicine and integrating traditional medicine products into health systems.

\section{Method}

\section{Research design}

To understand the inner content and logic of market access framework of CPM products into healthcare security systems in China, this paper used a documentary analysis approach [11] as a qualitative research method [12]. This research design is reviewed and approved by the University of Macau (MYRG2020-00230-ICMS).

\section{Data collection}

For data collection, all the documentary materials were collected from four sources. First, government documents were collected from the NHSA (http://www.nhsa. gov.cn), the NMPA (http://www.nmpa.gov.cn) and the NHC (http://www.nhc.gov.cn) as three key ministries that are involved in designing and implementing market access polices. Except direct search on their official websites, we have reviewed the annual policy collections published by the ministries since 2018 when the NHSA was officially founded.

Second, we collected formal documents of market access publicized from the CPM manufacturers that have supplied CPM products according to the reimbursement list (2020). Third, we searched the China National Knowledge Infrastructure to identify academic publications about the market access of CPM products since 2018 . Fourth, we searched online through Baidu search engine (http://www.baidu.com) to collect industrial analysis reports about market access of CPM products released by investment banks. Such kind of diversified strategies ensure that we can collect sufficient documents to meet the criteria of data saturation and to conduct triangular test for data validity.

\section{Data analysis}

For data analysis, we followed the thematic analysis method proposed for qualitative data analysis [13]. First, after familiarizing with all the materials, we analyzed the materials by dividing two types of CPM products: innovative brand $C P M$ products and generic CPM products. Second, considering the whole life cycle CPM products within the healthcare security system, we analyzed the market access mechanisms of CPM products from three aspects: entry, price adjustment, and exit. Finally, mechanisms (including applicable criteria and processes) for these two types of CPM products were identified respectively.

\section{Results}

The mechanisms of the access, price adjustment and exit for innovative CPM and generic CPM can be summarized as Fig. 1. Each mechanism is presented in details as below.

\section{Mechanism of new entry of innovative brand CPM products into the national reimbursement list: Price negotiation}

For innovative brand CPM products (or so-called exclusive CPM products in China), which usually have no competitor drugs and have not been included into the reimbursement list before, the NHSA established the new entry mechanism to manage the access application of innovative brand CPM products. The focus of this new entry mechanism is price negotiation.

To apply for price negotiation, the CPM firms need to submit a series of safety, efficacy (effectiveness) and 


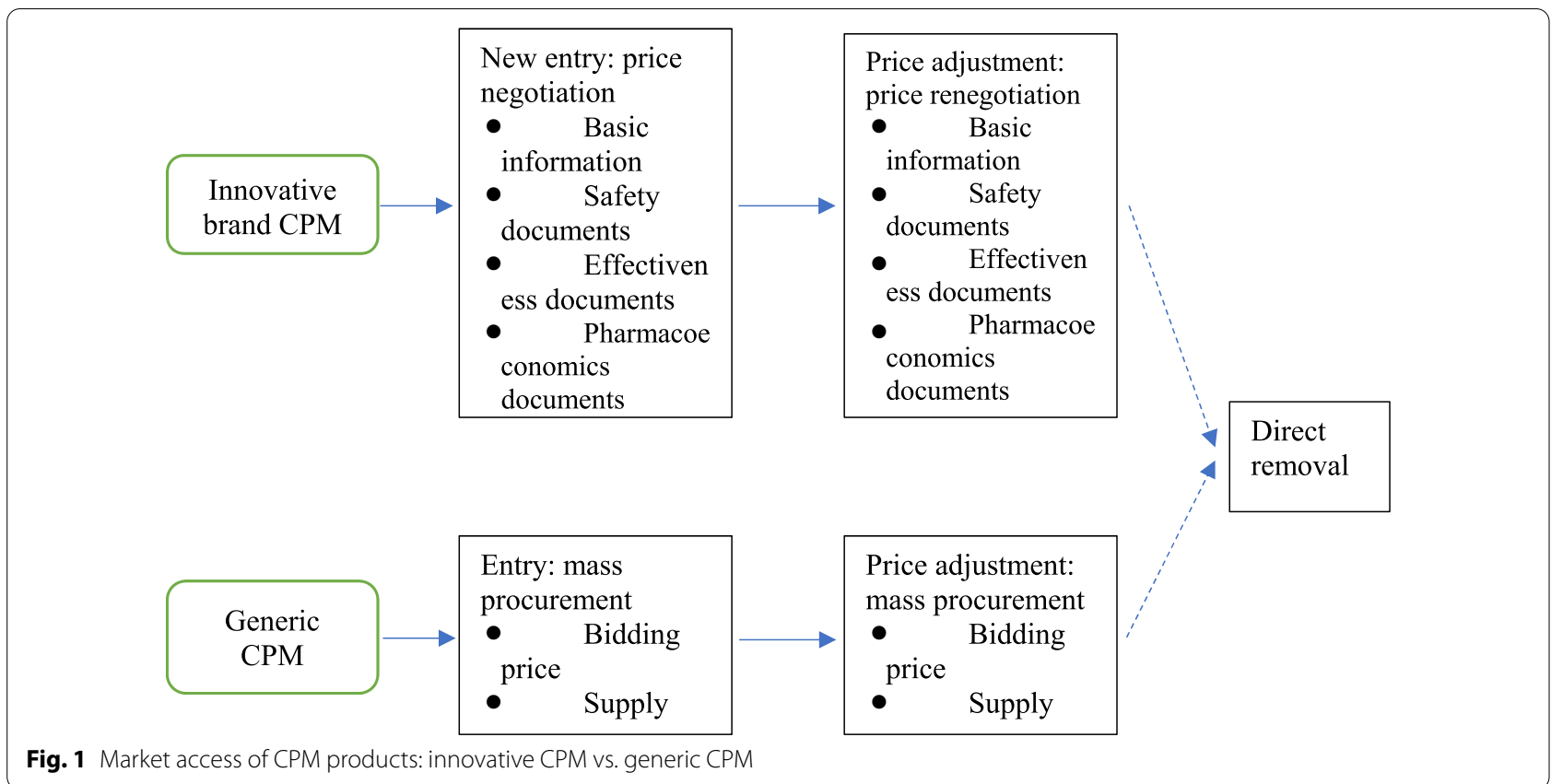

pharmacoeconomics documents about their innovative brand CPM products, including:

- Basic information (such as general name, time to market at home country and abroad, main indications, brief usage and dosage, and indications to be negotiated for access, etc.);

- Safety documents (such as RCT or adverse reactions in the real-world, etc.);

- Effectiveness documents (such as main clinical outcome indicators, differences in efficacy (effectiveness) compared with similar drugs or therapies, and clinical guidelines recommendations, etc.);

- Pharmacoeconomics documents (such as overall results of cost-effectiveness analysis, overall results of budget impact analysis, current domestic and foreign prices, charity donation plans, comparison with reference drug prices and total direct medical cost, and domestic and foreign medical insurance access, etc.);

After receiving the application documents, the expert panels organized by the NHSA will evaluate the clinical and pharmacoeconomics documents submitted by the CPM firms. Moreover, the expert panels will carry out evidence-based pharmacy evaluation, cost-effectiveness analysis, and budget impact analysis by themselves and generate independent report and recommended price.

With the independent report and recommended price, the representatives of the NHSA will meet the representatives of the CPM firms fact-to-face to negotiate the price. If the price proposed by the CPM firms fall into the range of the recommended price set by the expert panels, a final reimbursement price will be reached. Otherwise, the price negotiation will fail and the innovative brand CPM product will not be included into the national reimbursement list.

\section{Mechanism of price adjustment of innovative brand CPM products within the national reimbursement list: Price re-negotiation}

Except the mechanism of new entry to include innovative brand CPM products into the national reimbursement list, the NHSA realizes that it also needs to dynamically manage the innovative brand CPM products that have been listed in the national reimbursement list. Therefore, the NHSA established the mechanism of price change to implement dynamic adjustment of price or payment scope of innovative brand CPM products within the national reimbursement list. According to the regulation of the NHSA, such kind of mechanism is applied for three types of situations, including:

1. Negotiated drugs that are within the valid period of the agreement and need to re-determine the payment standard in accordance with the agreement.

2. Drugs that are necessary to adjust the scope (treatment field) of payment, according to the firm application or expert evaluation.

3. Drugs whose prices/expenses are obviously higher and that have taken up a large amount of healthcare 
security funds in recent years, compared with other drugs in the same treatment field.

The focus of such mechanism is price re-negotiation. The whole process is similar with that of new entry of innovative brand CPM products: first, CPM firms need to submit documents about basic information, safety, effectiveness, and pharmacoeconomics evaluation, et; second, the NHSA will organize expert panel to conduct independent evaluation to generate evaluation report and recommended price; third, the NHSA representatives and firm representatives will have face-to-face negotiation to reach an agreement price if negotiation succeeds.

For example, in 2020 six CPM products within the national reimbursement list have proceeded price change mechanism to remain in the national reimbursement list (see Table 1). Before re-negotiation, each of the six CPM products had cost more than 1 billion $\mathrm{CNY}$ in the healthcare security system every year. Through price re-negotiation, it is expected the national healthcare security system can save about $50 \%$ funding for the six CPM products.

\section{Mechanism of generic CPM products into healthcare security system: mass procurement for entry/price adjustment}

For generic CPM products that are manufactured by several companies, mass procurement is the mechanism for them to get access to healthcare security system, including new entry into the healthcare security system and making price adjustment. In practice, responding to the call for mass procurement application publicized by the healthcare security department, manufacturers can submit their bidding documents by indicating their bidding price and supply capacity. The healthcare security department will compare the bidding price submitted and usually select the 2-3 manufactures with the lowest price as final CPM product suppers.

Different from the centralized drug procurement organized by the central NHSA for generic chemical drugs, currently mass procurement for generic CPM products is only organized at provisional or city level. The reason is that the NMPA has only founded the consistency evaluation regulation for generic chemical drugs. Because CPM products still face the challenges of clarifying composition, the NMPA is still unable to organize consistency evaluation for CPM products. Consequently, the NHSA decided to leave the mass procurement to provisional level or city healthcare security departments.

Table 1 CPM products re-negotiated within the national reimbursement list (2020)

\begin{tabular}{|c|c|c|c|c|c|c|}
\hline & Name & Drug classification & Ingredient & Dosage & Indication & Price in 2020 list \\
\hline 1 & Kanglaite injection & $\begin{array}{l}\text { Dispel syndromes and } \\
\text { dispel masses }\end{array}$ & Coix Seed Oil & Injection & $\begin{array}{l}\text { Primary non-small cell } \\
\text { lung cancer and primary } \\
\text { liver cancer }\end{array}$ & • 136 CNY (100 ml:10 g) \\
\hline 2 & Kangai injection & $\begin{array}{l}\text { Replenish vital energy and } \\
\text { strengthen the body's } \\
\text { immune function }\end{array}$ & $\begin{array}{l}\text { Astragalus, ginseng, } \\
\text { matrine }\end{array}$ & Injection & $\begin{array}{l}\text { Primary liver cancer, lung } \\
\text { cancer, rectal cancer, } \\
\text { malignant lymphoma, } \\
\text { gynecological malignancy }\end{array}$ & $\begin{array}{l}\cdot 11.7 \text { CNY }(5 \mathrm{ml}) \\
\cdot 19.94 \text { CNY }(10 \mathrm{ml}) \\
\cdot 33.9 \text { CNY }(20 \mathrm{ml})\end{array}$ \\
\hline 3 & Salvianolate injection & $\begin{array}{l}\text { Invigorate blood circula- } \\
\text { tion, remove blood stasis, } \\
\text { and relieve pulse }\end{array}$ & $\begin{array}{l}\text { Salvia miltiorrhiza poly- } \\
\text { phenolate }\end{array}$ & Injection & Stable angina pectoris & $\begin{array}{l}\cdot 31.69 \text { CNY }(50 \mathrm{mg}) \\
\cdot 53.88 \text { CNY }(100 \mathrm{mg}) \\
\cdot 91.60 \text { CNY (200 mg) }\end{array}$ \\
\hline 4 & Danhong injection & $\begin{array}{l}\text { Promote blood circulation } \\
\text { and remove blood stasis }\end{array}$ & Salvia, safflower & Injection & $\begin{array}{l}\text { Chest pain, chest tight- } \\
\text { ness, coronary heart } \\
\text { disease }\end{array}$ & $\begin{array}{l}\cdot 5.05 \text { CNY }(2 \mathrm{ml}) \\
\cdot 17.32 \text { CNY }(10 \mathrm{ml}) \\
\cdot 29.44 \text { CNY }(20 \mathrm{ml})\end{array}$ \\
\hline 5 & Lanqin oral liquid & $\begin{array}{l}\text { Clear heat and detoxify, } \\
\text { relieve throat and swelling }\end{array}$ & $\begin{array}{l}\text { Radix isatidis, scutellaria } \\
\text { baicalensis georgi, garde- } \\
\text { nia, cork, sterculia }\end{array}$ & Oral liquid & $\begin{array}{l}\text { Acute pharyngitis, sore } \\
\text { throat, dry throat, burning } \\
\text { throat caused by lung and } \\
\text { stomach heat syndrome }\end{array}$ & $\begin{array}{l}\cdot 3.46 \mathrm{CNY}(10 \mathrm{ml}) \\
\cdot 5.88 \mathrm{CNY}(10 \mathrm{ml})\end{array}$ \\
\hline 6 & Bailing Capsule & $\begin{array}{l}\text { Nourish lungs and } \\
\text { kidneys, nourish essence } \\
\text { and qi }\end{array}$ & $\begin{array}{l}\text { Fermented cordyceps } \\
\text { fungus powder (Cs-C- } \\
\text { Q80) }\end{array}$ & Capsule & $\begin{array}{l}\text { Treatment of kidney } \\
\text { disease, treatment of type } \\
2 \text { diabetes with micro- } \\
\text { albuminuria, treatment } \\
\text { of recurrent urinary tract } \\
\text { infections, treatment of } \\
\text { liver diseases, treatment } \\
\text { of respiratory diseases, } \\
\text { adjuvant treatment of } \\
\text { tumors, etc. }\end{array}$ & $\begin{array}{l}\cdot 0.51 \text { CNY }(0.2 \mathrm{~g}) \\
\cdot 1.03 \text { CNY (0.5 g) }\end{array}$ \\
\hline
\end{tabular}




\section{Mechanism of exit from the national reimbursement list:} direct removal

For the CPM products that have been included into the national reimbursement list, the NHSA also established the mechanisms of direct removal to enable dynamic adjustment to eliminate the unsuitable drugs. Such kind of mechanism applies for two kinds of conditions:

1. Drugs of which the drug approval documents have been revoked or cancelled by the NMPA;

2. Drugs of which the risk is considered to be greater than the benefit after comprehensive evaluation of their clinical value, adverse reactions, pharmacoeconomic value, and other factors.

To implement of the exit mechanism, the NHSA annually scans the reimbursement list with reference to the official announcement of the NMPA, the reimbursement data of provisional SSAs, the adverse reaction reports from the NMPA and hospitals, etc., in order to identify the CPM products of potential concerns. Then, the NHSA will organize specific expert panel which may compose of clinical experts, clinical pharmacy experts, and pharmacoeconomics experts to carry out systematic evaluation based on the current evidence available without any input from the CPM firms. If the final benefitrisk report is negative, the CPM product will be directly removed from the reimbursement list without interactions with the CPM firms.

For example, in the national reimbursement list (2000), three CPM products were directly removed through such mechanism (see Table 2). Coptis Phellodendron Burn Ointment and Ginseng Astragalus Eleven Flavor Tablets/Capsules were removed because the manufacturers no longer existed. While Loquat Leaf Cream still has 15 production approvals, it is directly removed because its clinical value is deemed inadequte and it can be replaced by other drugs with equivalent or better curative effect in the reimbursement list.

\section{Discussion}

Through systematic documentary research, this paper identified four mechanisms that are applied to regulate the market access of CPM products to healthcare security system in China, which are not critically reported in the past literature. These findings raise some issues that are worth further discussion for innovative brand CPM products and generic CPM products respectively.

For innovative CPM products, it shows that the NHSA of China is trying to found a value-based market access framework for CPM products. For innovative conventional medicine products, developed countries have established a market access framework that depends on health technology assessment and price negotiation [14, $15]$. But there is no such a mature framework for traditional medicine products until now. In China, referring to the market access framework for innovative conventional medicine products, the NHSA is trying to apply an evidence-based price negotiation for innovative brand CPM products. Thus, the NHSA requires manufacturers to submit their evidence documents, conducts internally independent assessment, and then organize face-toface price negotiation to decide the final market access for innovative brand CPM products. The market access framework for innovative brand CPM products by the NHSA then provides a starting mode for future improvement of market access for traditional medicine product internationally.

However, it is noteworthy that there are two key differences between innovative conventional medicine

Table 2 CPM products directly removed from the national reimbursement list (2020)

\begin{tabular}{|c|c|c|c|c|c|c|}
\hline & Name & Drug classification & Ingredient & Dosage & Indications & $\begin{array}{l}\text { Production } \\
\text { approval }\end{array}$ \\
\hline 1 & Loquat Leaf Cream & $\begin{array}{l}\text { Nourishing lungs and } \\
\text { reducing phlegm }\end{array}$ & $\begin{array}{l}\text { Loquat leaves, supplemented } \\
\text { with sucrose }\end{array}$ & Ointment & $\begin{array}{l}\text { Lung heat cough, Less phlegm } \\
\text { and dry throat }\end{array}$ & 15 \\
\hline 2 & $\begin{array}{l}\text { Coptis Phel- } \\
\text { lodendron Burn } \\
\text { Ointment }\end{array}$ & Antipyretic and antidote & $\begin{array}{l}\text { Coptis, Phellodendron, Garcinia } \\
\text { (made), Borneol }\end{array}$ & Ointment & $\begin{array}{l}\text { Used for the treatment of } \\
\text { superficial and deep second- } \\
\text { degree burn wounds, the } \\
\text { area of medication should not } \\
\text { exceed } 3 \% \text { of the body surface } \\
\text { area }\end{array}$ & 0 \\
\hline 3 & $\begin{array}{l}\text { Ginseng Astra- } \\
\text { galus Eleven Flavor } \\
\text { Tablets/Capsules }\end{array}$ & Invigorate the spleen & $\begin{array}{l}\text { Ginseng, Astragalus, Angelica, } \\
\text { Gastrodia, Rehmannia, Alisma, } \\
\text { Cassia, Antler, Cuscuta, Asarum, } \\
\text { Chinese wolfberry, etc. }\end{array}$ & Tablets/capsules & $\begin{array}{l}\text { Used for the leukopenia caused } \\
\text { by radiotherapy and chemo- } \\
\text { therapy in cancer, and dizziness, } \\
\text { dizziness, fatigue, weight loss, } \\
\text { nausea, vomiting and other } \\
\text { symptoms caused by radio- } \\
\text { therapy and chemotherapy. }\end{array}$ & 0 \\
\hline
\end{tabular}


products (chemical drugs and biopharmaceutical drugs) and innovative brand CPM products though the general administrative processes of market access are the same. Firstly, while the major source of evidence about the efficacy of innovative conventional medicine products relies on randomized controlled trials, the effectiveness of the innovative brand CPM products is primarily based on real-world data. Due to the limitations in conducting randomized controlled trials with innovative brand CPM products, the effectiveness evidence of innovative brand CPM products based on real-world data is permitted and accepted [16, 17]. Secondly, regarding pharmacoeconomic evidence, while innovative conventional medicine products usually need to choose the competing products in the same category as comparators, innovative brand CPM products generally are required to choose the competing conventional medicine products for the same disease indication as comparators for pharmacoeconomic evaluation purposes. In general, it shows that amid the methodological challenges for innovative brand CPM products, the authorities of healthcare security systems are trying to develop alternative ways for assessing market access of innovative brand Chinese medicine.

For generic CPM products, it shows that the NHSA of China is experimenting to establish an institutional market access framework for generic CPM products through price competition on the basis of quality assurance. This market access framework is different from that of innovative brand CPM products, because generic CPM products have usually been approved and used clinically for years, which has demonstrated their effectiveness and safety. As general CPM products usually have several manufacturers to supply, bidding price often play the decisive role in final market access results. However, quality assurance will be the prerequisite factor for market access of generic CPM products, particularly considering the effects of manufacturing processes on CPM product quality [18]. In China, while quality standards for generic CPM products have been included into the China Pharmacopeia, the NMPA of China has not organized the consistency evaluation for generic CPM products yet [19]. Because of the scientific and technological challenges in evaluating CPM products, how to conduct consistency evaluation for generic CPM products remains debating [20-22]. Future development of consistency evaluation for generic CPM products will affect the design and operation of market access framework for generic CPM products in the long run.

While this paper mainly focuses on market access of CPM products into healthcare security system in China, the findings of this paper also have several implications for international integration of traditional medicine products into health systems. First, there should be separated market access frameworks for innovative traditional medicine products and generic traditional medicine products. Considering the different innovation nature and evidence accumulation, such kind of separated arrangement for innovative and generic traditional medicine products is necessary. Second, systematic evaluation including efficacy (effectiveness), safety and economic elements should be pre-conditions for market access of traditional medicine products. Notably, realworld evidence needs to be encouraged and applied for traditional medicine products [23]. Third, pharmacoeconomic evaluation of traditional medicine products should be an indispensable part of market access of traditional medicine products $[24,25]$. Considering the pharmacoeconomic value of traditional medicine products from the perspective of payers will pave the way of traditional medicine products for smoother market access internationally [26].

To our knowledge, this is the first paper that studies the market access of CPM products into healthcare security system. However, there are some research limitations that can be addressed in future studies. First, this papers only used the documentary materials for analysis. As practitioners such as the NHSA officials, industrial management and clinical experts, etc., have their own idea and judgement in the realistic practice of CPM market access, future studies could conduct qualitative interviews with first-line practitioners to collect their opinions about the barriers and suggestions for improving market access of CPM products. Second, mass procurement for generic CPM products is only experimentally operating at provincial or city level. Future studies on mass procurement of generic CPM products to establish a formal framework of centralized mass procurement is necessary. Third, the market access to healthcare security system is different from the access to hospital. Particularly in China, entry into the national reimbursement list does not guarantee direct access to individual hospital formulary. How to promote the inclusion of CPM products on the national reimbursement list into the individual hospital formulary is another important but complex topic. Future study focuses on enlistment of CPM products into hospital formulary is needed. Fourth, it is necessary to evaluate the long-term impact of the CPM market access policies. In particular, mathematical modelling methods based on first-hand real-world data should be developed to help assess and optimize the market access policies for CPM products.

\section{Conclusions}

China has established market access framework of CPM products by focusing on price negotiation for innovative brand CPM products and mass procurement for generic 
CPM products. Further studies of CPM products based real-world data are needed to provide solid clinical and pharmacoeconomic evidence to support market access of CPM products into healthcare security systems.

\author{
Abbreviations \\ CPM: Chinese patent medicine; NHC: National Health Commission; NHSA: \\ National Healthcare Security Administration; NMPA: National Medicinal Prod- \\ uct Administration.
}

\section{Acknowledgements}

The authors would like to thank the help from Dr. Wei Li at the China Pharmaceutical University.

\section{Authors' contributions}

$\mathrm{CX}$ and $\mathrm{HH}$ conceptualized this study. DY, $\mathrm{YL}$ and $\mathrm{HH}$ collected the materials and conducted analysis. CX, DY, YX, and HH drafted the manuscript. All authors read and approved the final manuscript.

\section{Funding}

This research is supported by the Grants from the University of Macau (MYRG2019-00025-ICMS; MYRG2020-00230-ICMS). It is also partially supported by the Foshan Medicine Dengfeng Project of China (2019-2021).

\section{Data availability}

All data generated or analysed during this study are included in this published article.

\section{Declarations}

\section{Ethics approval and consent to participate}

This study is approved by the Ethic Committee at the University of Macau (MYRG2020-00230-ICMS). Consent to participate is waived because no human participants are involved in this study.

\section{Consent to publish}

Not appliable.

\section{Competing interests}

The authors would like to declare that there is no issue related to conflict of interest for this study.

\begin{abstract}
Author details
'Southern Medical University Affiliated Maternal \& Child Health Hospital of Foshan, Foshan 528000, China. ${ }^{2}$ School of Pharmaceutical Sciences, Southern Medical University, Guangzhou 510150, China. ${ }^{3}$ State Key Laboratory of Quality Research in Chinese Medicine, Institute of Chinese Medical Sciences, University of Macau, Macao, SAR, China. ${ }^{4}$ School of Public Health and Management, Guangzhou University of Chinese Medicine, Guangzhou, China. ${ }^{5}$ Department of Public Health and Medicinal Administration, Faculty of Health Sciences, University of Macau, Macao, SAR, China.
\end{abstract}

Received: 7 September 2021 Accepted: 22 December 2021 Published online: 04 January 2022

\section{References}

1. Yuan $H, M a$ Q, Ye L, Piao G. The traditional medicine and modern medicine from natural products. Molecules. 2016;21(5):559.

2. Jamshidi-Kia F, Lorigooini Z, Amini-Khoei H. Medicinal plants: past history and future perspective. J Herbmed Pharmacol. 2018;7(1):1-7.

3. Park YL, Canaway R. Integrating traditional and complementary medicine with national healthcare systems for universal health coverage in Asia and the Western Pacific. Health Systems Reform. 2019;5(1):24-31.

4. Li J, Zhu J, Hu H, Harnett JE, Lei Cl, Chau KY, Chan G, Ung CO. Internationalization of traditional/complementary medicine products: market entry as medicine. Chin Med. 2018;13:50.
5. Wang S. Assessing the issue of market access of TCMP in EU Pharmaceutical Law. In Market Access of Traditional Chinese Medicinal Product in the EU under WTO Legal Framework. Springer, Cham; 2020. pp.81-121.

6. Lin AX, Chan G, Hu Y, Ouyang D, Ung CO, Shi L, Hu H. Internationalization of traditional Chinese medicine: current international market, internationalization challenges and prospective suggestions. Chin Med. 2018;13:9.

7. Cyranoski D. Why Chinese medicine is heading for clinics around the world. Nature. 2018;561(7724):448.

8. Yuan L, Wu ZA, Shao ML. Evolution of the registration regulations for proprietary Chinese medicines in China. Chin J Nat Med. 2017;15(1):4-11.

9. Fan TP, Zhu Y, Leon C, Franz G, Bender A, Zheng X. Traditional Chinese Medicine herbal drugs: from heritage to future developments. In The Science and Regulations of Naturally Derived Complex Drugs. Springer, Cham; 2019. pp.59-77.

10. Liang Z, Lai Y, Li M, Shi J, Lei Cl, Hu H, Ung CO. Applying regulatory science in traditional chinese medicines for improving public safety and facilitating innovation in China: a scoping review and regulatory implications. Chin Med. 2021;16:23.

11. Dalglish SL, Khalid H, McMahon SA. Document analysis in health policy research: the READ approach. Health Policy Plann. 2021;35(10):1424-31.

12. Bowen GA. Document analysis as a qualitative research method. Qual Res J. 2009;9(2):27-40

13. Braun V, Clarke V. Using thematic analysis in psychology. Qual Res Psychol. 2006:3(2):77-101.

14. Akehurst RL, Abadie E, Renaudin N, Sarkozy F. Variation in health technology assessment and reimbursement processes in Europe. Value in Health. 2017;20(1):67-76.

15. Oortwijn W, Mathijssen J, Banta D. The role of health technology assessment on pharmaceutical reimbursement in selected middle-income countries. Health Policy. 2010;95(2-3):174-84.

16. Shi J, Hu H, Harnett J, Zheng X, Liang Z, Wang YT, Ung COL. An evaluation of randomized controlled trials on nutraceuticals containing traditional Chinese medicines for diabetes management: a systematic review. Chin Med. 2019;14(1):1-20.

17. Du H, Kuang TT, Qiu S, Xu T, Huan CLG, Fan G, Zhang Y. Fecal medicines used in traditional medical system of China: a systematic review of their names, original species, traditional uses, and modern investigations. Chin Med. 2019;14(1):1-6.

18. Pan J, He S, Zheng J, Shao J, Li N, Gong Y, Gong X. The development of an herbal material quality control strategy considering the effects of manufacturing processes. Chin Med. 2019;14(1):1-2.

19. Leong F, Hua X, Wang M, Chen T, Song Y, Tu P, Chen XJ. Quality standard of traditional Chinese medicines: comparison between European Pharmacopoeia and Chinese Pharmacopoeia and recent advances. Chin Med. 2020;15(1):1-20

20. Fan TP, Deal G, Koo HL, Rees D, Sun H, Chen S, Dou JH, Makarov VG, Pozharitskaya ON, Shikov AN, Kim YS. Future development of global regulations of Chinese herbal products. J Ethnopharmacol. 2012;140(3):568-86.

21. Rui-Wen ZH. Traditional Chinese medicine: research and development, globalization, and regulation. Chin J Nat Med. 2017;15(1):1-3.

22. Alostad AH, Steinke DT, Schafheutle El. Herbal medicine classification: policy recommendations. Front Med. 2020;7:31.

23. Tian F, Xie Y. Real-world study: a potential new approach to effectiveness evaluation of traditional Chinese medicine interventions. J Chin Integr Med. 2010;8(4):301-6.

24. Wang X, Wang ZF, Xie YM, Zhang W, Liao X, Chang YP. Guideline for postmarketing Chinese medicine pharmacoeconomic evaluation. Chin J Integr Med. 2015;21(6):473-80.

25. Si L, Yin M, Wang J, Yang S, Zhang J, Wei L. Evaluation of quality of pharmacoeconomic studies involved in traditional Chinese medicine in China. Exp Rev Pharmacoecon Outcomes Res. 2020 (online first)

26. Yang L, Chen X, Ung CO, Zhu H, Hu H, Han S. Clinical and economic evaluation of salvianolate injection for coronary heart disease: a retrospective study based on national health insurance data in China. Front Pharmacol. 2020;11:887.

\section{Publisher's Note}

Springer Nature remains neutral with regard to jurisdictional claims in published maps and institutional affiliations. 